\title{
Review of glass fiber grid use for pavement reinforcement and APT experiments at IFSTTAR
}

\author{
Mai Lan Nguyen* $\square$ Juliette Blanc* $\square$ Jean Pierre Kerzrého* \\ Pierre Hornych*
}

* LUNAM Université, IFSTTAR

Infrastructures and Mobility Department

Route de Bouaye CS4

44344 BOUGUENAIS Cedex, FRANCE

mai-lan.nguyen@ifsttar.fr

juliette.blanc@ifsttar.fr

jean-pierre.kerzreho@ifsttar.fr

pierre.hornych@ifsttar.fr

\begin{abstract}
Reinforcement using an interlayer system has been demonstrated for more than four decades as a multi-purpose solution to improve performance, to extend service life and thus to reduce maintenance costs of road pavements. Among a large number of existing interlayer systems, glass fiber grids have shown effective use in pavement reinforcement with a hot mix asphalt overlay. Recently they have received increasing attention from the pavement community. However, as for other types of interlayer systems, the mechanisms underlying the effectiveness and proper installation of this type of reinforcement system are still not fully understood, and the choice of the most appropriate grid (e.g. mesh size, tensile strength) and its optimal location in the pavement system are mainly based on experience. This paper presents firstly a literature review on the use of glass fiber grids in pavement reinforcement. Then some results of recent full scale tests on the accelerated pavement testing facility of the IFSTTAR are presented. They confirm that glass fiber grid properly installed near the bottom of the asphalt layer improves significantly the fatigue life of the reinforced pavement. They also demonstrate the efficiency of glass grid use under only a thin asphalt overlay. Finally, first results obtained using an original instrumentation of glass grid strands by means of strain gages, to understand better the mechanical behaviour of the glass fiber reinforcement in a new pavement structure are described.

KEYWORDS: Glass fiber grid, Reinforcement, Asphalt pavement, Reflective cracking, Accelerated Pavement Testing
\end{abstract}




\section{Introduction}

Interlayer systems have been receiving increasing attention from the pavement community as efficient reinforcement solutions for pavements, to delay crack initiation and propagation. However the mechanisms underlying the mechanical behaviour of these interlayer systems are not fully understood, and the most appropriate interlayer systems, and their optimal location in the pavement system are still a subject of discussion

Although the range of commercially available interlayer products is very wide, the large variety of products can be classified in a limited number of categories (Vanelstraete and Franken, 1997; COST Action 348, 2006; South Africa, 2008). They include:

- sand asphalt,

- SAMIs (Stress Absorbing Membrane Interlayers),

- paving fabrics or geotextiles,

- paving grids (steel, glass fiber and polymeric),

- composites thereof.

During the last two decades, numerous research studies on the use of different interlayer systems in pavement structures have been carried out at IFSTTAR in France. The systems evaluated include polypropylene paving grids or glass fiber grids (Kerzrého et al., 2010; Kerzrého et al., 2011; Hornych et al., 2012), nonwoven geotextiles (Artières et al., 2012) and steel meshes (Florence, 2005), used for the reinforcement of unbound or bound pavement layers.

Recently, interest has focused mainly on the use of paving grids, particularly glass fiber grids, and composites thereof, placed in asphalt layers, to develop reliable, robust and cost-effective (structural) maintenance techniques (de Bondt, 2012). Use of grids as reinforcement in asphalt layers poses more difficulties than application in unbound layers, due to the greater tensile strain levels, and/or risk of debonding at the level of the grid.

Paving grids, used in asphalt layers, for reinforcement of a deteriorated pavement, or between new asphalt layers can have several purposes: they can function as moisture barriers, stress relieving interlayer and reinforcement. Their use can reduce reflective cracking, water infiltration and development of fatigue cracking. Their main disadvantages may be poor bonding with the asphalt material and difficulties to recycle the reinforced asphalt materials.

Actually, there is no research publication that covers all general aspects of glass fiber grid application in pavement structures. This paper concentrates on the use of glass fiber grids for pavement reinforcement. It is divided in two parts: 
- A literature review, presenting the characteristics of glass fiber grids, test methods for evaluating their performances, and methods used for design and construction of grid-reinforced pavements.

- An experimental part, which presents results of some recent studies on the behaviour of glass-fiber grid reinforced pavements, carried out on the accelerated pavement testing (APT) facility of IFSTTAR.

\section{Literature review on glass fiber grid use for pavement reinforcement}

\subsection{Glass fiber grids}

Glass fiber grid is an interlayer reinforcement product. It is placed between the leveling layer or existing pavement and the new asphalt overlay, and becomes the hidden strength in the road. It retards reflective cracking by dissipating the horizontal stresses induced by the cracks.

Glass fiber presents interesting properties as a reinforcing material. It is both strong and flexible. It is thermally and chemically stable at bituminous mix temperatures of $200^{\circ} \mathrm{C}$. It is not affected by de-icing salt, petroleum or bitumen.. Glass fiber has a Young s modulus of approximately $70 \mathrm{GPa}$, which is almost 20 times higher than typical asphalt concrete modulus at around $20^{\circ} \mathrm{C}$ (Darling and Woolstencroft, 2004), and a high tensile strength. Therefore, glass fiber reinforcement clearly provides the axial stiffness required to redirect crack energy (de Bondt, 1999a). The European Standard EN 15381 allows manufacturers to describe geotextiles and geotextile-related products, including glass fiber grids, on the basis of declared values for characteristics relevant for use in pavements and asphalt overlays, such as tensile strength, elongation at maximum load, durability, melting point, etc .... and if tested to the specified method.

The prefabricated glass fiber grid is generally impregnated by a polymer coating for multiple purposes. The polymer coating allows higher compatibility and adhesion with asphalt, longer-lasting mechanical performance and protection against various chemicals and abrasive materials. According to de Bondt (1999b), based on field experience, big differences in coating quality exist between the glass fiber grid products available on the market. Due to these differences, some products which are initially cheaper, because of their lower coating quality, may be, in the end, much less cost-effective, due to their poor performance in the field.

Glass fiber grids have a square or rectangular open mesh form (Figure 1a). The open structure facilitates aggregate interlock between paving courses, restrains lateral movement of the aggregates, and thus greatly decreases shear potential which is common with paving fabrics. The open grid structure enhances through-hole bearing capacity and allows more stress to transfer to the grid by means of the interlocking aggregates of the asphalt layers (Lee, 2008). Geometrically, while a 
square mesh allows equal lateral movement of aggregates in both directions, a rectangular mesh restricts more lateral movement in one direction than the other. The mesh size generally varies from $12.5 \mathrm{~mm}$ up to $40 \mathrm{~mm}$, depending on maximum aggregate size. According to Vanelstraete and Franken (1997), the mesh width has to be sufficiently large in comparison with the maximum grain size of the asphalt overlay, in order to allow the aggregates to penetrate through the mesh. Otherwise, inadequately compacted spots may remain after overlaying or insufficient adhesion with the overlay may be the result. Jaecklin and Scherer (1996) reported that fine glass grid meshes reduce interlocking and adhesion and are therefore problematic.

a)
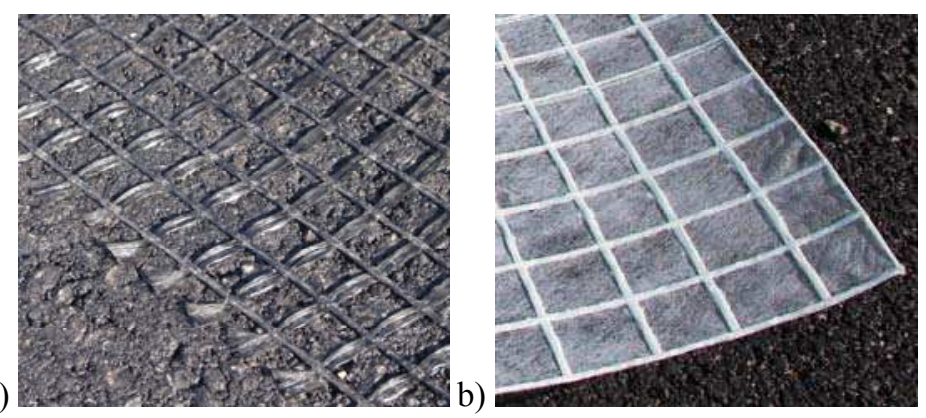

Figure 1. A regular glass fiber grid (a) and glass grid associated with a light polyester nonwoven (b).

Glass fiber grids are generally used with a tack coat to enhance their performance. Aldea and Darling (2004) indicated that regardless of the coating used, the addition of coating significantly improved the initial tensile performance. Moreover, using polymeric coating significantly improved the efficiency of the interlayer as compared to the uncoated and emulsion-coated glass grid. The results of this study also indicated that not only the type of coating influences the grid performance, but also the coating process. Voids which remain at the interface may create debonding and have detrimental effects on grid performance. Hakimzadeh and al. (2012) used a new adhesion test (a fracture-energy based interface bond test) to study different coating procedures and demonstrated that samples produced with different tack coat application rates give different fracture bond energies.

The installation procedure of glass fiber grids is very important to ensure a good bonding between the grid and the asphalt layers. For that reason, several techniques have been developed to facilitate installation. Some glass grids incorporate a stable, pressure-sensitive adhesive at the back, which allows quick and easy installation.

Glass fiber grid associated with a light polyester nonwoven (about $15-40 \mathrm{~g} / \mathrm{m}^{2}$ ) is also largely used (Figure 1b). The nonwoven acts as an interface between the tack coat and the tires of vehicles during construction. It can absorb an excess of binder of the tack coat and help to better distribute it. According to Vanelstraete \& Franken 
(1997), an excess of binder can lead to problems during construction. The binder may stick to construction vehicle tires and lead to detachment of the interlayer product from the underlying layer. An insufficient quantity of binder indeed leads to improper functioning of the interlayer due to delamination by poor bonding. Moreover, the light polyester non-woven allows aggregates of the asphalt mixtures to pass through easily and thus ensures aggregate interlocking between layers.

When a watertight seal of the underlying pavement structure is required and on uneven bases, such as milled surfaces or concrete structures, a heavier nonwoven geotextile or fabric (more than $100 \mathrm{~g} / \mathrm{m}^{2}$ ) combined with regular glass grid can be used. In such a composite paving grid, the bitumen-impregnated nonwoven is designed to have a SAMI effect and the grid a reinforcing function.

Recently, a new range of glass grids which consists of a regular glass grid and an additional multilayer thermoplastic tack film has been developed. This tack film melts partially at typical asphalt temperatures during the application of the hot overlay. The tack film is designed to enhance the bond between layers of asphalt and replace the use of conventional tack coats. It simplifies the installation of the grid since there are no emulsion spray trucks, curing delays, variability in tack coat application rate, or risk of adhesion of the tack coat on the wheels of the construction vehicles.

Glass fiber grids can be used for localized pavement repairs (reinforcement of concrete joints, crack repair) or for full width coverage of the entire pavement. They can be used in all climates (cold temperate and hot climate zones) and geographic areas, performing equally well in desert conditions and in near arctic regions that are subject to intense cold and seasonal temperature fluctuations (Darling and Woolstencroft, 2004). Their applications can be found not only in road pavements (Doligez, 2009), but also in airfield pavements (de Bondt, 2000; Penman and Hook, 2008; Buonsanti et al., 2012), port platforms and industrial facilities.

\subsection{Test methods for glass fiber grid applications}

Many studies have been conducted over the last 30 years in order to characterize the effectiveness of interlayer systems for pavement reinforcement. A review of laboratory testing as well as full scale evaluations of glass fiber grid applications is presented here.

\subsubsection{Laboratory tests}

Vanelstraete \& Franken (1997) identified two main types of tests to study the effect of interlayer systems: 
- Tests to determine the adhesion of the interlayer system with asphalt layers. The adhesion will depend on the fixing method/layer, the quantity of the coating, and also on the type of interlayer product.

- Laboratory tests to investigate the resistance to crack propagation of a reinforced structure. Here, the effect of a given interlayer system may depend on the exact loading conditions (repeated thermal loading, traffic loading).

\subsubsection{Adhesion tests}

Many adhesion test methods have been developed during the last 30 years. The active Technical Committee (TC) 237-SIB of the RILEM (International union of laboratories and experts in construction materials, systems and structures) distinguishes two categories of adhesion test methods: destructive tests (torque tests, tensile tests, wedge splitting tests, shear tests) and non-destructive tests on existing pavements (Portable Seismic Pavement Analyzer, Colibri test, Hammer test, Falling Weight Deflectometer). According to Raab et al. (2009), shear testing is recognized as a good and effective method for testing the interlayer bond of asphalt pavements. A first interlaboratory test was organized during the TC 206-ATB of the RILEM in order to compare the different shear test procedures to assess interlayer bonding properties in asphalt pavements (Piber et al. 2009). This interlaboratory test showed generally good agreement between different unidirectional monotonic static shear tests.

According to the literature review, the Leutner shear test (Figure 2a), originally developed in Germany (Leutner, 1979), is one of the most widely used tests to assess bonding condition of glass fiber grid reinforcements (and other interlayer systems). Plug and de Bondt (2010), using a modified Leutner test, evaluated the adhesion of glass fiber grid reinforcement in asphalt overlays after different curing periods of the tack coat. Results showed that the shear strength of the tack coat interface increases with time after construction.

Recently, Vismara et al. (2012) using adhesion tests, demonstrated that, when glass fiber grid is associated with a nonwoven polypropylene, this composite grid led to a good bond at the interface of the reinforced specimens. In fact, the authors performed traditional Leutner shear tests and indirect tensile tests on double-layer specimens with and without the above composite reinforcement. The results showed that the asphalt specimens presented a brittle behaviour without the composite interlayer and a ductile behaviour with the composite, despite higher values of shear and tensile strength in the specimens without the composite. Tests results also showed that the composite reinforced system prevents the separation of the two halves of the specimen. 
a)
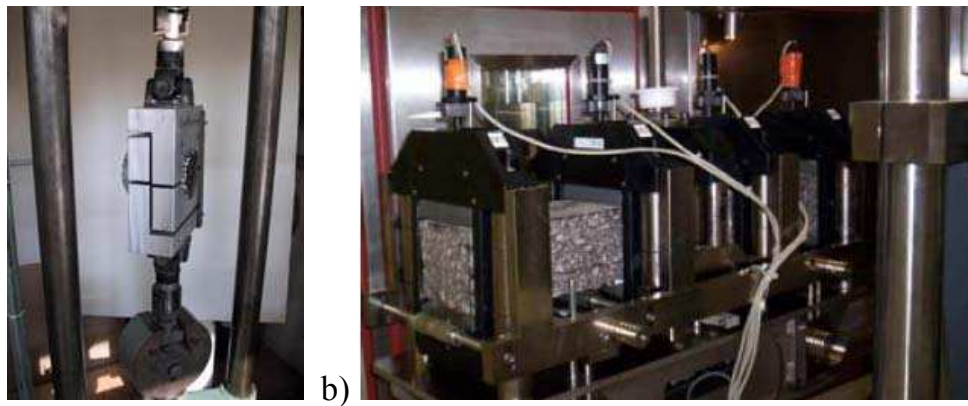

Figure 2. Two main laboratory test methods to study glass fiber grid reinforced asphalt mixtures: a) Modified Leutner shear test (Nguyen et al., 2012); b) Four point bending test (Arsenie et al., 2012)

\subsubsection{Cracking resistance tests}

Evaluation of cracking resistance is mostly based on bending tests on grid reinforced beams, under static or cyclic loading. These tests generally show the efficiency of grid reinforced specimens. Bacchi (2009) and Arsenie et al. (2012) performed cyclic four point bending tests on beam specimens (Figure 2b), to compare the fatigue behavior of a standard bituminous mixture and the same bituminous mixture reinforced with glass fiber grid associated with a light polyester nonwoven. The glass fiber grid was placed at the bottom side of the reinforced beams. Finite Element modeling was also used by Arsenie et al. (2012) to simulate damage evolution of the specimens. The asphalt damage prediction model of Bodin (2002), implemented in a finite element code, was applied. Both laboratory tests and first modelling results from these studies pointed out an improvement in fatigue life of the grid reinforced beams.

Many other laboratory studies have been conducted to evaluate cracking resistance of glass fiber grid based reinforcement systems under traffic loading or thermal loading, particularly at Texas A\&M University (Lytton, 1988), Delft University (de Bondt, 1999a) and University of Nottingham (Brown et al., 2001). These studies indicated that glass fiber grid reinforcement performed significantly better than any other type of geosynthetic, as well as unreinforced systems, due to the very high stiffness of the glass fibers.

\subsubsection{Test for evaluation of installation damage}

Another test method which is of interest for both manufacturers and designers is a damage test which allows determining the amount of installation damage caused to the reinforcement. During installation, the reinforcement may be subjected to high loads due to construction traffic and this may reduce its tensile strength. According to Hufenus et al. (2005), a laboratory procedure for the simulation of damage during installation of geosynthetics used for reinforcement of soil structures is specified in the prestandard prEN ISO 10722-1. The principle of this test consists in placing the 
geosynthetic between two compacted aggregate layers, and submitting it to vertical cyclic loading. The tensile strength of the geosynthetic is then controlled after this damage simulation. This test procedure is planned to be extended to paving grids (including glass fiber grids) for asphalt layer reinforcement in a next European standardization work program.

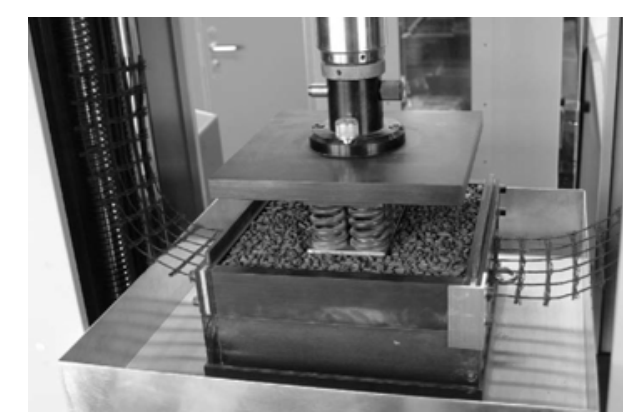

Figure 3. Test equipment for simulating damage during installation (Hufenus et al., 2005)

\subsubsection{Full scale pavement performance evaluations}

Laboratory tests have various limitations, due for instance to limited dimensions of the tested specimens. Furthermore, adhesion laboratory tests allow to characterize only the interlayer bonding condition. Bending tests, in case of testing for sandwich paving grid reinforced specimens, produce in some cases too favorable results, due to ideal bonding conditions. Therefore, full scale accelerated pavement tests or field tests are necessary to validate the laboratory results, and evaluate in more realistic conditions the performance of glass fiber grids or other types of interlayer systems.

Some results of full scale pavement tests from the literature are presented in this paragraph. With increased use, the efficiency of glass fiber grids as reinforcement has improved, due to improved installation procedures, better understanding of their mechanical behavior, as well as better considerations in pavement design.

\subsubsection{Rehabilitation of jointed concrete pavements}

Marks (1990) evaluated the effectiveness of one of the first generations of glass grid for preventing reflective cracking in rehabilitation of a jointed concrete pavement. Annual monitoring after four years indicated that glass grid placed directly on top of the concrete pavement was more effective at preventing reflective cracking than glass grid between lifts of asphalt concrete resurfacing. The study concluded also that the use of glass grid yields a small reduction in reflective cracking compared to a solution without reinforcement, but not sufficient to justify additional expense for the use of this reinforcement product. 
In another research on field performance of various rehabilitation techniques also for jointed concrete pavements, one test section in which glass grid was installed, in strip application on top of the joints, between two lifts of asphalt overlay failed prematurely (Scullion and Von-Holdt, 2004). Alligator cracking and moisture accumulation at the interface between the overlay and the grid were evident from a Ground Penetrating Radar survey. A control section without reinforcement on the same road segment performed relatively well. The authors attributed the poor performance of the grid to debonding between the interlayer and the surrounding asphalt layers as evident from extracted cores. In another test section in which fullwidth application of the grid was used, delamination occurred between the grid and the upper asphalt overlay.

\subsubsection{Reinforcement of flexible and composite pavements}

Darling and Woolstencroft (2000) evaluated the performance of glass grids for retarding reflective cracking through monitoring of two test sites. Both evaluation sites, originally constructed by means of full depth flexible and composite pavements, exhibited severe transverse and longitudinal cracking. A standard glass grid was installed over the full width of the pavement in both sites while a heavy grid was used at three major intersections on construction joints on the first site. Prior to rehabilitation, milling of 50 to $100 \mathrm{~mm}$ of the existing HMA and repairing of the most severe cracks and patches were realized. The glass grids were then placed between two lifts of asphalt overlay. After four years of monitoring, on both sites, the glass grid reinforced sections performed very well with less reflective cracking compared to the control sections.

Bush and Brooks (2007) evaluated five different reinforcement types including fiber-glass grid on an experiment of a flexible pavement that suffered from transverse cracking. Only strip application of the interlayer was evaluated in this study by placing it on top of the existing cracks. A $50 \mathrm{~mm}$ overlay was then placed over the treated sections. Performance was monitored annually using visual surveys for the period from 1999 to 2007 . Results of this study showed that fiber-glass grid was the interlayer that performed the best, helping to retard the severity of cracks.

It has to be underlined that many other related studies on full scale pavements (e.g. Powell, 2008) or on real pavements (e.g. Doligez, 2009) have been realized, not including private research work by manufacturers or transportation agencies that has not been officially published. In general, full scale and field evaluations showed that, in case of properly installed glass fiber grids, with appropriate properties, reinforcement can help to retard reflective cracking. However, no significant improvement in terms of rutting or deflection directly due to the use of glass fiber grid compared to unreinforced solutions has been demonstrated. A full scale experiment performed at IFSTTAR presented further in the paper confirms these observations. 


\subsection{Reinforcement mechanisms and design considerations}

Glass fiber grids and composites thereof act principally as a reinforcement interlayer system helping to delay reflective cracking. Based upon earlier work in the literature, the reinforcement mechanism of geosynthetics used in pavements seems to be better understood (Al-Qadi et al., 2008). Button and Lytton (1987) summarized this reinforcement mechanism as follows:

- The crack starts to propagate (due to thermal and traffic loading or uneven soil movements) from its original position upward until it reaches the reinforcement layer;

- If the interlayer is stiff enough (stiffer than the surrounding materials), the crack will turn laterally and move along the interface until its energy is exhausted.

- Based on this mechanism, a reinforcement interlayer may contribute to the structural capacity of the pavement.

Lytton (1989) noted that the reinforcement failure would develop only after debonding has occurred between the lower layer and the interlayer.

According to Rathmayer (2007), Khay and Giraud (2004), beside regular design parameters (i.e. deterioration mechanisms, loading conditions, properties of road materials and pavement, construction equipment and procedures), models or design guidelines for reinforcement of asphalt layers and overlays also have to take into account two other design parameters:

- Properties of the material for reinforcement (e.g. tensile strength),

- Interaction between the reinforcement product and surrounding materials (e.g. bonding condition).

Actually, some simplified design models and procedures are available, but no one takes into account all these design parameters in a consistent way. Therefore, design is still to a large extent based on experience and is also product specific. Among several models and procedures which are currently used in practice in Europe (COST Action 348, 2006), the two following procedures could be applied for glass fiber grid reinforcement application:

- The Anti-Reflective Cracking Design Software (ARCDESO ${ }^{\circledR}$ ), which has been developed by Ooms Nederland Holding, can analyze many maintenance solutions for reflective cracking within a short period of time. The software is based on modeling of crack propagation in the pavement, using a finite element model. The effectiveness of reinforcement versus reflective cracking can be assessed and compared with observed field performance.

- The University of Nottingham approach deals with reflective cracking, with and without grid reinforcement. The method estimates the growth of a crack 
under three specific loading modes which induce cracking damage, with two programs (OLCRACK for traffic induced cracking and THERMCR for thermal induced cracking).

In the US, the Texas Department of Transportation (TxDOT) has also developed a design procedure for pavement overlays with a reinforcing geosynthetic and a design check program (FPS-21) for the expected reflection cracking life of the overlay in flexible pavements (Button and Lytton, 2003).

By lack of space, more details on mechanical action of glass fiber grid based reinforcement systems, their modeling and their design procedures are not presented in this paper. They will be the subjects of a specific publication.

\subsection{Construction recommendations}

Like other types of reinforcement, to provide significant enhancement to a pavement system, glass fiber grids need to be properly selected and installed with high attention. Presently, many manufacturers and transportation agencies provide construction specifications and installation guidelines for specific reinforcement product applications. The most important considerations when selecting a glass grid product are: aperture size, tensile strength, grid coverage (detail repairs or full width coverage), moisture barrier properties (associated with a nonwoven fabric). For installation procedures, most guidelines give some of the following recommendations:

- Surface preparation: glass fiber grid must be placed on a smooth, level, clean and dry surface. Any surface that is not finely milled may require a levelling course of about 20 to $50 \mathrm{~mm}$. Potholes and open cracks must be treated prior to grid installation.

- Placement of grid: the surface of the grid must be rolled with a rubber-coated or pneumatic tired roller to improve bonding.

- Tack coat is recommended for promoting stronger interface bonding. Tack coat must cure before placing the asphalt overlay.

- A minimum overlay thickness of $40 \mathrm{~mm}$ must be used.

- Specialist installation is required.

The installation of the reinforcement system and its interaction with the surrounding layers is an important issue to ensure its effectiveness. A good bonding between the reinforcement grid and the asphalt layers is necessary even though the glass grid is stiff enough. Baek et al. (2010), studying the effects of interface conditions on reflective cracking development in asphalt overlays, showed that the effect of interface bonding strength on global fracture behaviour is more important than that of interface tangential stiffness. Based on field experience of glass-grid 
interlayers, Steinberg (1992) noticed that the benefit of glass-grid interlayer could be questionable due to improper installation. Easy handling of the products by the workers on site and proper respect of the installation procedures are important to obtain good performance.

Concerning the location of the glass fiber grid in a pavement system, no optimum position has been found from the literature. Main application of glass fiber grids concerns reinforcement of cracked pavements, or layers for prevention of reflective cracking. According to Virgili et al. (2009) glass grid begins to work only when a high tensile stress is reached at the interface or the crack tip grows up to grid ribs. To be more effective, the grid should be placed where high tensile stresses are acting. However, $\mathrm{Wu}$ and Walubita (2009) indicated that cracking can either be bottom-up or top-down initiated, depending on the location of the maximum horizontal tensile stresses and strains in the asphalt layer. Various factors such as the pavement structure and wheel/tire loading configurations influence both the location and magnitude of the crack-related tensile strains.

Glass fiber grids are, in practice, usually placed near the bottom of the asphalt layers. Many construction guidelines recommend the use of a levelling course of 20 to $50 \mathrm{~mm}$ before placement of the reinforcement grid, then $40 \mathrm{~mm}$ minimum of asphalt overlay. However, Kerzrého et al. (2010) demonstrated that, in case of a cracked bituminous pavement which still showed a structural capacity, the section reinforced with an open glass grid placed under a thin asphalt overlay $(25 \mathrm{~mm})$ performed better than two unreinforced sections (one with the same overlay thickness and one with a thicker overlay).

\section{Full scale tests on the IFSTTAR APT facility}

From the literature review presented in this paper, glass fiber grid based reinforcement systems have shown mixed results, particularly in field evaluations. It is noticed that published studies do not often present and analyze unsuccessful experiments, and sometimes the test methods used are not appropriate to evaluate global effectiveness of the reinforcing products.

This part presents results of two full scale experiments performed on the IFSTTAR full scale APT facility, to evaluate the performance of different glass fiber grids, in two different applications: the maintenance of a damaged flexible pavement, and the improvement of the fatigue resistance of a new pavement. The advantage of these tests is to allow testing of the structures up to failure, under controlled loading conditions. Few such full scale experiments with fiber glass grids have been reported. 


\subsection{The IFSTTAR APT facility}

The IFSTTAR accelerated pavement testing facility (APT), in Nantes, is an outdoor circular carousel dedicated to full-scale pavement experiments, carried out with public and/or private partners. The carousel consists of a central tower and four arms (each $20 \mathrm{~m}$ long) equipped with wheels, running on a circular test track (Figure 4). The experimental circular pavement has a mean radius of $17.5 \mathrm{~m}$ and a width of $6 \mathrm{~m}$, and thus a total length of approximately $110 \mathrm{~m}$. The position of the loading module can be adjusted for different radii on each arm, for instance to test simultaneously the effect of different load configurations. During loading, a lateral wandering of the loads can be applied to simulate the lateral distribution of loads of real traffic (Autret et al., 1988; Autret and Gramsammer, 1990; Gramsammer et al., 1999).

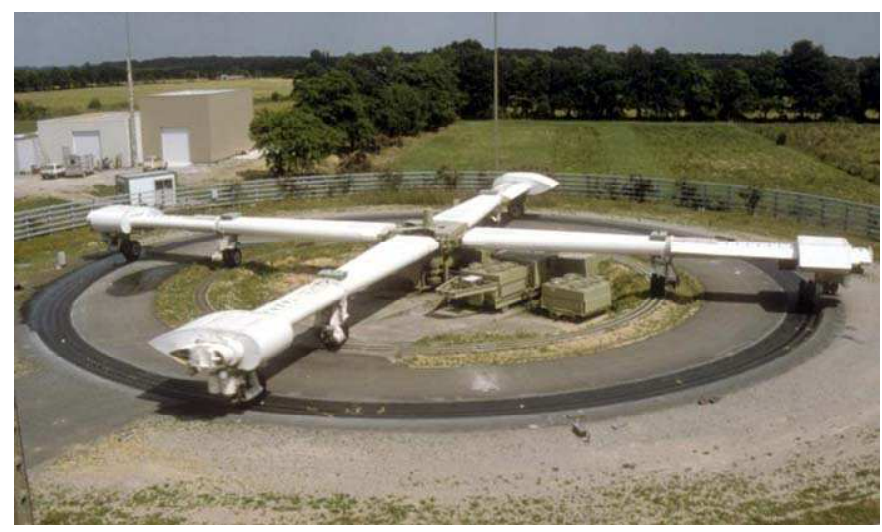

Figure 4. View of the IFSTTAR fatigue test track.

\subsection{Full scale test on new reinforced pavements}

The full scale experiment was carried out on the large pavement fatigue carrousel of IFSTTAR in Nantes, to compare the behaviour of a section reinforced with a traditional grid with a tack coat (called section C) and of an unreinforced pavement section (called section D)

The four arms of the fatigue carrousel have been equipped with standard dual wheels. The loading speed was 6 rounds $/$ minute $(43 \mathrm{~km} / \mathrm{h})$. The loading program started in April 2011. Until September 2011, 1 million $65 \mathrm{kN}$ loads (standard French equivalent axle load) were applied. Between January 2012 and March 2012, 200000 additional loads at $70 \mathrm{kN}$ were applied. During the experiment, loading has been stopped approximately every 100000 cycles to perform various distress measurements. A detailed presentation of the experiment can be found in Hornych et al. (2012). 


\subsubsection{Test section and material characteristics}

The tests were carried out on typical French low traffic pavement structures consisting of an $80 \mathrm{~mm}$ thick bituminous wearing course, over a granular subbase (300 mm thick), and a sandy subgrade soil, with a bearing capacity of about $95 \mathrm{MPa}$. The reinforced structure was $10 \mathrm{~m}$ long and $3 \mathrm{~m}$ wide. The grid was placed in the lower part of the bituminous layer, $2 \mathrm{~cm}$ above the interface with the subbase.

The bituminous mix is a standard French $0 / 10 \mathrm{~mm}$ wearing course bituminous material. This material contains $5.5 \%$ of grade $35 / 50$ bitumen. The mechanical behaviour of this mix was characterised by classical complex modulus and fatigue tests on trapezoidal specimens (EN 12697-31 and EN 12697-24). The specimens had an average void content of $6.2 \%$. The reference complex modulus of the mix at $15^{\circ} \mathrm{C}$ and $10 \mathrm{~Hz}$ is $11320 \mathrm{MPa}$. Experimentally, the fatigue parameters obtained for the mix are $\varepsilon 6=116 \mu$ strains and $b=-0.206$ (with a fatigue law: $\varepsilon_{t}=\varepsilon_{6}\left(N / 10^{6}\right)^{b}$ ).

\subsubsection{Characteristics of the tested grid}

The grid tested was a high-strength open fiberglass grid custom knitted in a stable construction and coated with a patent-pending elastomeric polymer and selfadhesive glue (Tensile Strength: $100 \mathrm{kN} / \mathrm{m} \times 100 \mathrm{kN} / \mathrm{m}$ ). The mesh of the grid was $\left(25 \times 25 \mathrm{~mm}^{2}\right)$.

\subsubsection{Construction}

The pavement structures were built on the existing subgrade of the test track, which is a sand with $10 \%$ fines, sensitive to water. The granular base consisted of $30 \mathrm{~cm}$ of $0 / 31.5 \mathrm{~mm}$ unbound granular material (UGM). A $2 \mathrm{~cm}$ thick bituminous layer was first laid and compacted on the 2 sections, with and without reinforcement. Then a tack coat with $300 \mathrm{~g} / \mathrm{m}^{2}$ of residual bitumen, was applied (Figure 5). The final $6 \mathrm{~cm}$ thick bituminous layer was laid on the 2 sections, and compacted with a rubber-tired roller.

a)

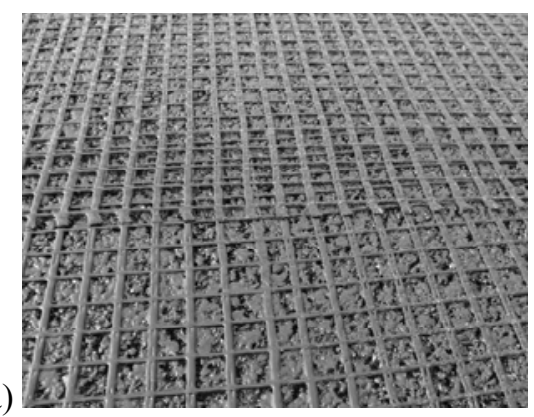

b)

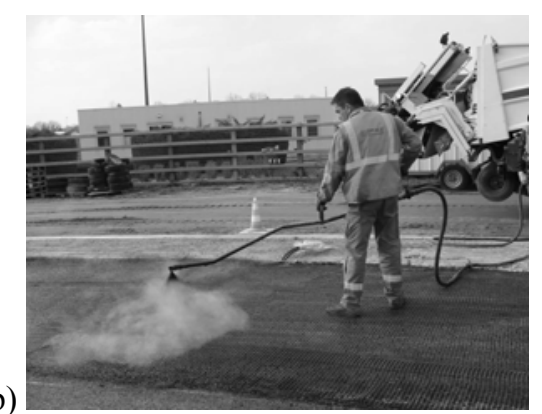

Figure 5. Construction: a) Grid of section C; b) Tack coat application 
The circular shape of the test sections required to cut the grids in relatively narrow bands, $5 \mathrm{~m}$ long by $1.5 \mathrm{~m}$ wide. To cover the test section, one $1.5 \mathrm{~m}$ wide band was placed on the centre of the wheelpath, and then two bands on each side.

\subsubsection{Results}

\subsubsection{Deflection and rut depth measurements}

Deflection measurement between the two wheels were performed using a Benkelman beam, under the $65 \mathrm{kN}$ load at about $3 \mathrm{~km} / \mathrm{h}$, after different numbers of load cycles. During all the experiment, no significant difference in deflection was observed between the reinforced section $\mathrm{C}$ and the unreinforced section $\mathrm{D}$.

Due to the lateral wandering of the loads, the width of the circulated area is 1.6 $\mathrm{m}$. The transverse profile of the pavement is measured using a 2 meters long ruler, every 3 meters, to determine the rut depth. Maximum rut depth measurements have been made at different load cycles, and also indicated that, on sections $\mathrm{C}$ and $\mathrm{D}$, the rut depths were very similar. After 1200000 cycles, the final rut depth was 14.6 $\mathrm{mm}$ for the reinforced section $\mathrm{C}$ and $16 \mathrm{~mm}$ for the unreinforced section D. There was no significant improvement for the reinforced section $\mathrm{C}$.

\subsubsection{Crack monitoring}

Crack percentage was determined by the ratio between the length of pavement with cracks and the initial length. The first cracks were observed on unreinforced section D after 800000 load cycles. Until 1.2 million of loads, the extent of cracking increased, reaching $70 \%$ at the end of the test. On this section D: first, very fine isolated transverse cracks appeared. Then, under traffic, these cracks started to open, and crushed fines started to come out due to a pumping effect. Other thin transverse cracks developed nearby. The transverse orientation of the cracks is typical of fatigue cracking observed on the carrousel, for pavements with relatively thin bituminous layers (about $8 \mathrm{~cm}$ ) (Hornych et al., 2008). Figure 6 presents the evolution of the extent of cracking, as a function of the level of traffic. It corresponds to the percentage of the length of the pavement affected by cracks (for a transverse crack, the affected length is considered, arbitrarily, to be $500 \mathrm{~mm}$ ). On reinforced section $\mathrm{C}$, no crack was observed until the end of the test. A significant improvement of crack resistance was therefore observed with the grid. 


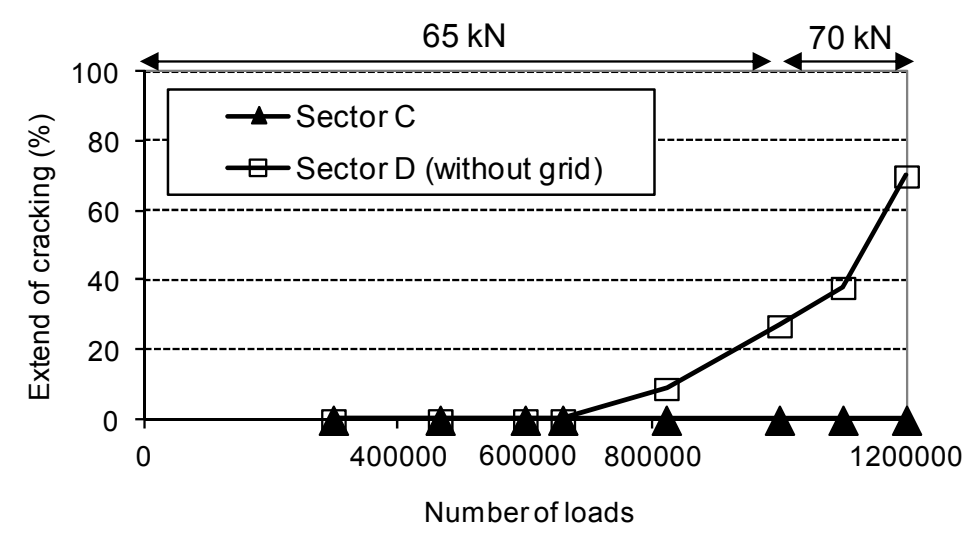

Figure 6. Extent of cracking, in percent, on the 2 sections

\subsubsection{Conclusion}

In this experiment, a classical fibreglass grid was tested as reinforcement of a new pavement, with relatively thin bituminous layers $(70 \mathrm{~mm})$; the objective was to evaluate the behaviour of the reinforced section, in comparison with a reference section without grid. It was concluded that:

- The levels of deflection were very similar on the reinforced and unreinforced sections.

- The levels of rutting were very similar on the reinforced and unreinforced sections.

- Cracking appeared first on section D (without grid) after 800000 cycles. At the end, $70 \%$ of the section D was cracked. Section C (reinforced by a grid) presented no cracking until the end of the test.

For this experiment with a new pavement, it was therefore confirmed that the classical grid increases significantly the fatigue resistance of the bituminous pavement layer (at least by a factor of two, but perhaps more, because it was not possible to continue further the test, to observe cracking on the reinforced section). Effect of the reinforcement on deflection and rutting did not appear significant.

\subsection{Full scale test of pavement reinforcement}

In connection with the European Project FORMAT (Fully Optimised Road Maintenance), three thin cracked pavement maintenance techniques were compared on the IFSTTAR fatigue test track ((Michaut et al., 2004) and (Balay et al., 2004)). The first maintenance technique consisted of a $4 \mathrm{~cm}$ layer of a thin bituminous 
concrete, the second of a very thin bituminous concrete $2,5 \mathrm{~cm}$ thick with a glass grid-reinforced lower part, and the third of a conventional very thin bituminous concrete $2.5 \mathrm{~cm}$ thick. The initially damaged structure exhibited extensive cracking of the bituminous layer. Although cracked, this pavement still showed a structural capacity with an average deflection of $55 \mathrm{~mm} / 100$ under a half axle load of 6.5 tonnes.

For this test, the four arms of the fatigue carrousel have been equipped with standard dual wheels. 3.3 million loads (over a 5 year period) were applied by dual wheels, with a load of $65 \mathrm{kN}$. The loading speed was 6 rounds $/$ minute $(43 \mathrm{~km} / \mathrm{h})$.

\subsubsection{Test section and material characteristics}

The damaged structure, with interface debonding, consisted of $6 \mathrm{~cm}$ of densegraded asphalt mix, $8 \mathrm{~cm}$ of road base asphalt, $20 \mathrm{~cm}$ of unbound granular material and a silty sand subgrade.

Before application of the treatment, the surface was milled on $2 \mathrm{~cm}$ or $3.5 \mathrm{~cm}$, in order to eliminate existing rutting and to have a smooth support for the geogrid. The three bituminous maintenance treatments have been applied in November 2003. The first sector $\mathrm{n}^{\circ} 5 \mathrm{a}$, has been overlaid with $40 \mathrm{~mm}$ of thin asphalt concrete (TAC). The second sector $\mathrm{n}^{\circ} 5 \mathrm{~b}$ has been overlaid with $25 \mathrm{~mm}$ of very thin asphalt concrete (VTAC) incorporating a glass grid (innovative treatment). The third sector, $\mathrm{n}^{\circ} \mathrm{cc}$, has received the same VTAC as the sector $n^{\circ} 5 b$, but without reinforcement grid.

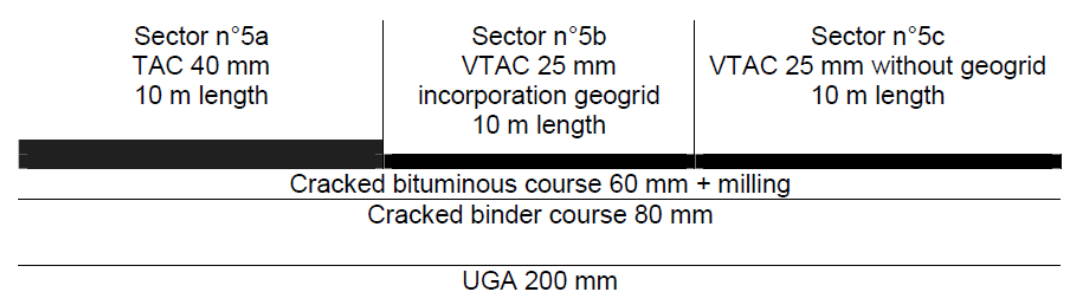

Figure 7. Structures after application of the maintenance treatments

\subsubsection{Characteristics of the tested grid}

The grid used was an open glass fiber grid coated with a special resin, associated with a light polyester non-woven. The mesh of the grid is $40 \mathrm{~mm} * 26 \mathrm{~mm}$. 


\subsubsection{Construction}

A tack coat with $300 \mathrm{~g} / \mathrm{m}^{2}$ of residual bitumen was applied on the planned surface and the grid was placed on the tack coat (see Figure 8). Another impregnation of $200 \mathrm{~g} / \mathrm{m}^{2}$ of residual bitumen was necessary for the grid. The final $25 \mathrm{~mm}$ thick bituminous layer was laid. Temperature of bituminous mixes was about $160^{\circ} \mathrm{C}$. The bituminous concrete was compacted with a steel roller compactor, with vibration for the TAC and without vibration for the VTAC.

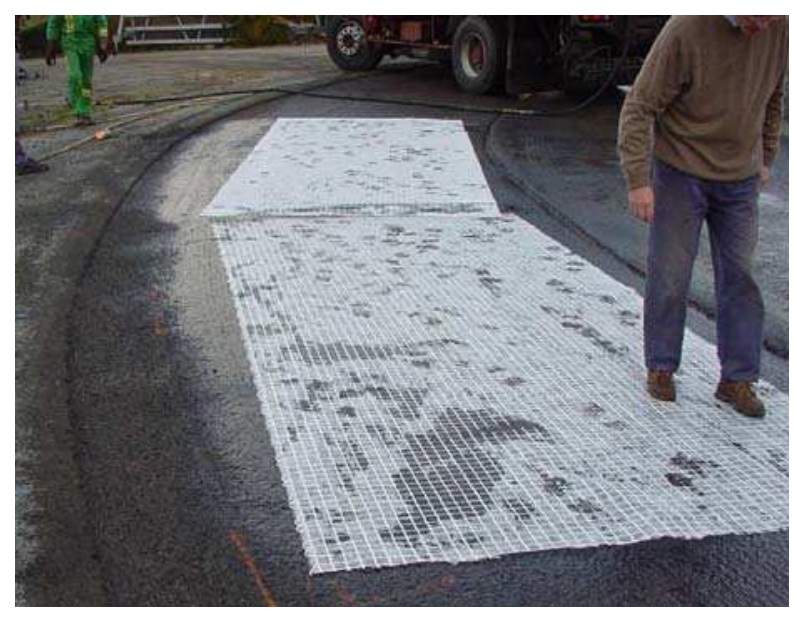

Figure 8. Geogrid after tack coat application on the structure

\subsubsection{Results of crack monitoring}

Measurements of extent of cracking in function of the number of loads are presented in Figure 9. The first cracks were observed on section $n^{\circ} 5 \mathrm{c}$ (VTAC without grid) after 430000 loads. Then cracks appeared on the section $\mathrm{n}^{\circ} 5 \mathrm{~b}$ (VTAC with grid) at 530000 loads, and on the section $n^{\circ} 5 \mathrm{a}$ (TAC) at 600000 loads.

The 3 maintained sections were kept in place on the APT during a period of 5 years, while testing other sections on the remaining part of the test track. During this period, 3.3 million $65 \mathrm{kN}$ loads were applied. At the end of the 3.3 million loads, the sections with TAC and VTAC were totally cracked. Section $\mathrm{n}^{\circ} 5 \mathrm{~b}$ with VTAC and glass grid presented only $10 \%$ of cracked surface (Kerzrého et al., 2010). 

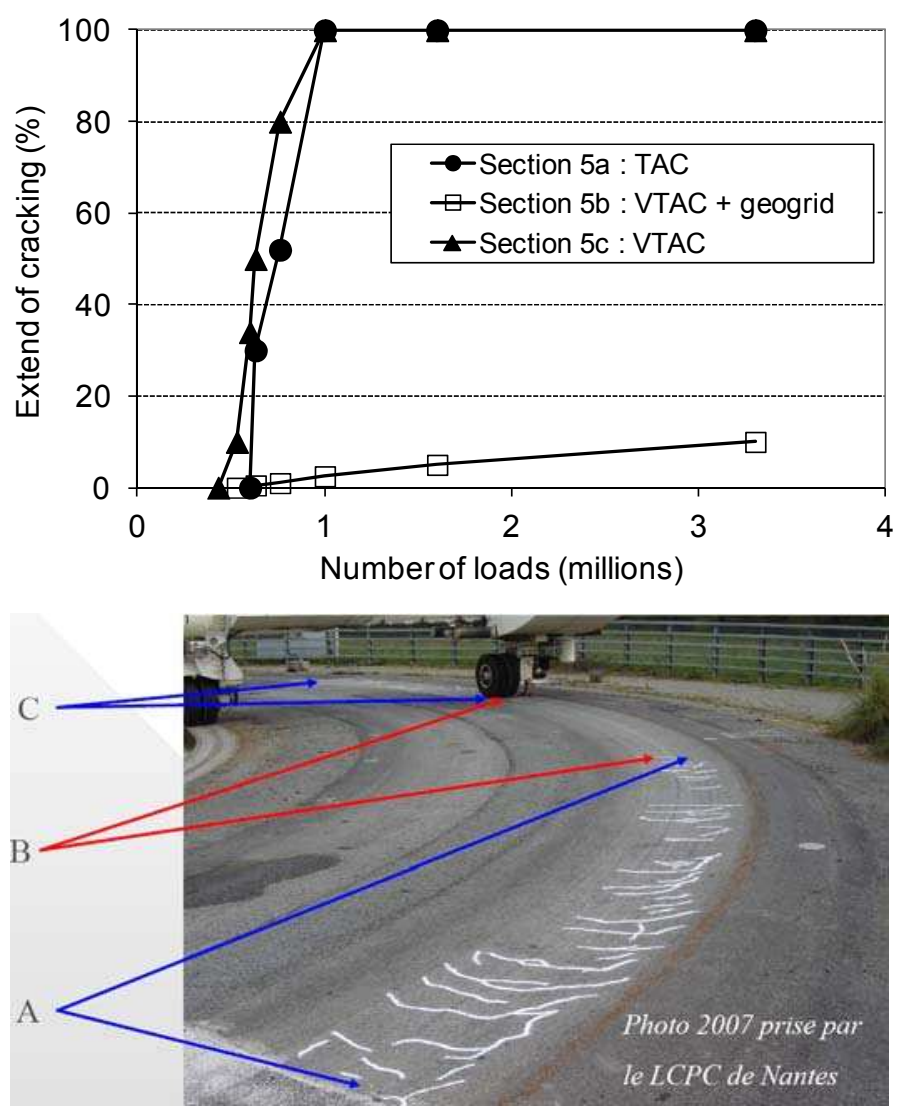

Figure 9. Extent of cracking (in percent) on the 3 sections and photo of the tested pavement at the end of the experiment.

In this experiment, interesting observations have also been made on the evolution of the interface between the existing pavement and the reinforcement. The three sections were built in November. The tack coat was applied on a cold support $\left(8\right.$ to $\left.10^{\circ} \mathrm{C}\right)$. Immediately after, the bituminous mixture was put on the tack coat, at the temperature of $160^{\circ} \mathrm{C} .1$ million loads were first applied on these structures, during a cold period (winter). Cores made after these 1 million loads indicated that there was some debonding between the support and the new bituminous overlays on all sections. This debonding could be due to the cold temperature of the support during construction. However, no ravelling of material and no important damage was observed on the three sections at this stage.

At the end of the test (5 years later, at 3.3 million loads), cores were made again on the three structures. On these cores, the overlays appeared, on the contrary, well bonded. It was assumed that this improvement of the interface resulted from the 
effect of traffic, and of high temperatures during the summer (up to $50{ }^{\circ} \mathrm{C}$ in the bituminous layers).

At the end of the test, slabs were cut from the structure with the glass grid. Figure 10 shows that the grid was perfectly integrated in the structure, and was in a good state.

a)

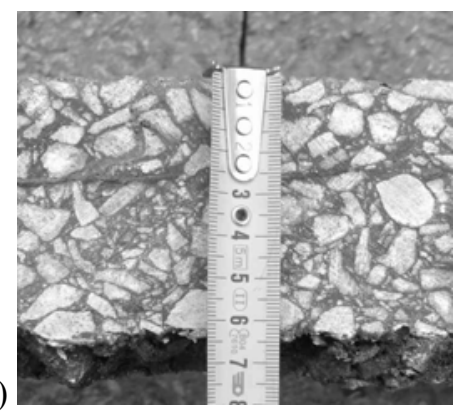

b)

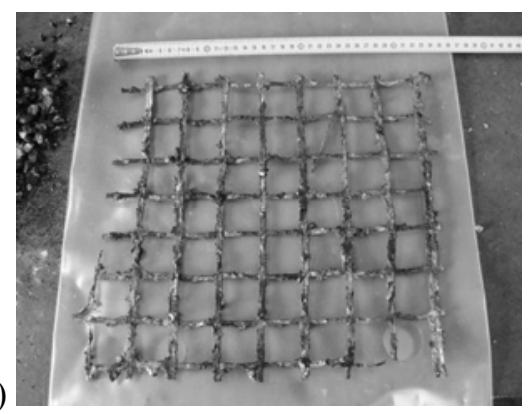

Figure 10. Grid in bituminous structure and grid at the end of the test

\subsubsection{Conclusion}

In this experiment, different solutions of reinforcement were tested :

- sector ${ }^{\circ} 5 \mathrm{a}: 40 \mathrm{~mm}$ of thin asphalt concrete (TAC);

- sector $\mathrm{n}^{\circ} 5 \mathrm{~b}: 25 \mathrm{~mm}$ of very thin asphalt concrete (VTAC) incorporating a geogrid;

- sector $n^{\circ} 5 \mathrm{c}$ : $25 \mathrm{~mm}$ of $\operatorname{VTAC}$ (as the sector $\mathrm{n}^{\circ} 5 \mathrm{~b}$, but without geogrid).

At the end of the 3.3 millions loads (applied during 5 years), the sections with TAC and VTAC were totally cracked. The section with VTAC and grid presented only about $10 \%$ of cracking, showing the very positive effect of the grid on crack development. It seems that the grid did not really delay the initiation of the first cracks (which appeared between 400000 and 600000 loads on all 3 sections), but then efficiently reduced the development of cracking. This is in agreement with the conclusions of the review made by de Bondt (2012), which indicate that under traffic loading grid reinforcements are mainly activated during crack propagation, and not during the first crack initiation phase. A modification of the state of the interface between the old pavement and the reinforcement was also observed (improvement of bond, after the effect of traffic and high summer temperatures). 


\section{Measurement of strains on a glass grid reinforcement}

In order to better understand the behaviour of a reinforcement grid in a structure, a piece of glass-fiber grid $(1 \mathrm{~m} \times 1 \mathrm{~m})$ was instrumented with 2 longitudinal and 2 transverse strain gages, glued directly on the mesh of the grid. This grid was placed on top of a thin layer of bituminous mix, $1 \mathrm{~cm}$ thick. The grid was covered by tack coat, and $7 \mathrm{~cm}$ of dense-graded asphalt mixture was laid.

The full scale experiment was carried out on the pavement fatigue carrousel of IFSTTAR in Nantes. The arms of the fatigue carrousel have been equipped with standard dual wheels. The tires used are Dunlop 1200 R20 SP321. The loading speed was 6 rounds/minute $(43 \mathrm{~km} / \mathrm{h})$. The loading program started in May 2012. Until the end of June 2012, 133500 loads were applied (standard $65 \mathrm{kN}$ French equivalent axle load).

\subsection{Characteristics of grid and strain gages}

The grid used was a classical fibreglass grid, with a mesh size of $21 \mathrm{~mm} * 21 \mathrm{~mm}$, including a thin non-woven geotextile. The strain gages used are Kyowa KFG-5$350-\mathrm{C} 1-11,30 \mathrm{~mm}$ length (Figure 11b), glued with X280 or N50 glue (HBM). The gages were protected with AK22 (HBM) and a metal strip (Figure 11a).

a)

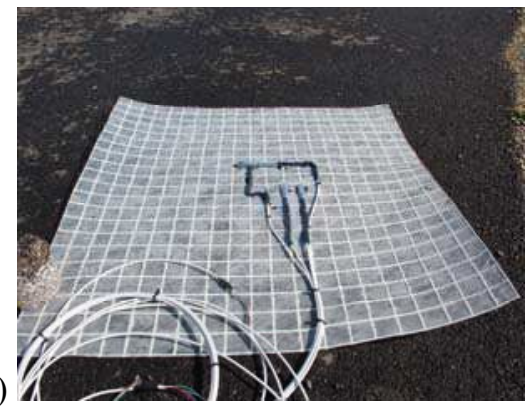

b)

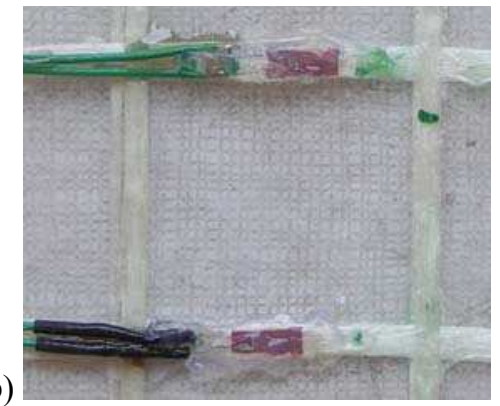

Figure 11. a) grid with 2 longitudinal and 2 transverse strain gages, b) detail of 4 strain gages, c) detail of strain gages

\subsection{Construction}

The pavement structures were built on the existing subgrade of the test track, which is a sand with $10 \%$ fines, sensitive to water. The granular base consisted of $30 \mathrm{~cm}$ of $0 / 31.5 \mathrm{~mm}$ unbound granular material (UGM). After construction, this base was covered by a spray seal. A $1 \mathrm{~cm}$ thick bituminous layer was first manually laid. The part of the grid was put on this bituminous layer. A tack coat with $300 \mathrm{~g} / \mathrm{m} 2$ 
of residual bitumen was applied on the grid. The final $7 \mathrm{~cm}$ thick bituminous layer was laid, and compacted with a steel drum vibrating roller. The bituminous mix was put in place at temperatures around $180^{\circ} \mathrm{C}$.

\subsection{Results}

\subsubsection{Strain signals under the centre of the dual wheel load}

Transverse and longitudinal strains were measured using the gages glued on the grid, under the centre of the dual wheel (so, in the middle of the wheel path). Figure 12 presents the shape of the signals, at a temperature of $21^{\circ} \mathrm{C}$, a speed $\mathrm{v}=43 \mathrm{~km} / \mathrm{h}$ and 53000 loads. Longitudinal strains indicate first a small contraction (positive strain) and then extension (under the centre of the dual wheels). Transverse strains indicate first extension, followed by contraction (under the center of the dual wheels). The quality of the signals is good, and qualitatively, the strain signals are very similar to those obtained using classical strain gages used on the APT facility for instrumentation of asphalt layers. The difference between the response of the two gages placed in the same direction is also very small.

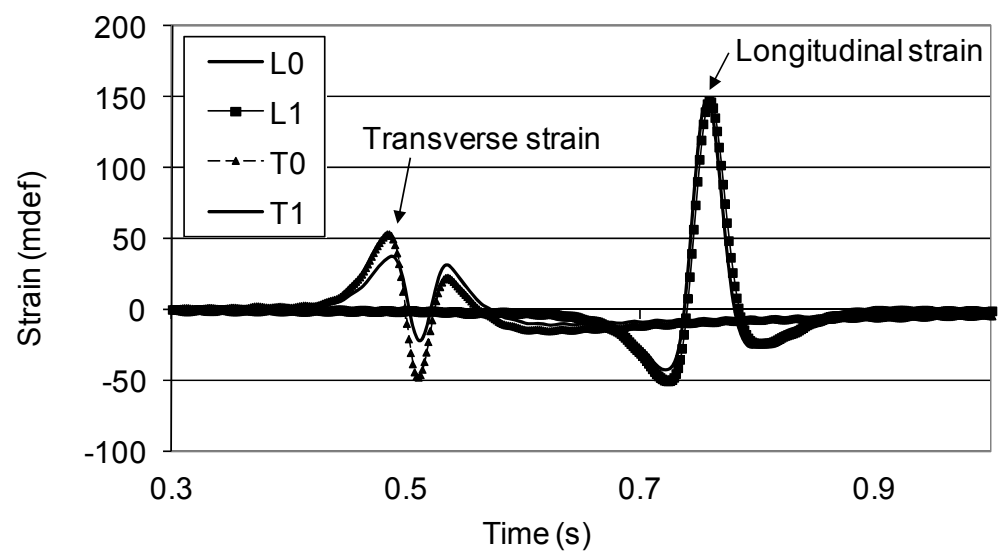

Figure 12. Signals of longitudinal and transverse strain gages under the center of a dual wheel, at $21^{\circ} \mathrm{C}, 53000$ loads, $V=43 \mathrm{~km} / \mathrm{h}$

\subsubsection{Strain signals under centre of one wheel}

Transverse and longitudinal strain measurements were also made under the centre of one wheel. Figure 13 presents the shape of the signals, at the temperature of $21^{\circ} \mathrm{C}$, a speed $\mathrm{v}=43 \mathrm{~km} / \mathrm{h}$ and 53000 loads. Longitudinal strain signals show first 
a small contraction and then extension (under the centre of the wheel). For transverse strains, only a large extension is observed.

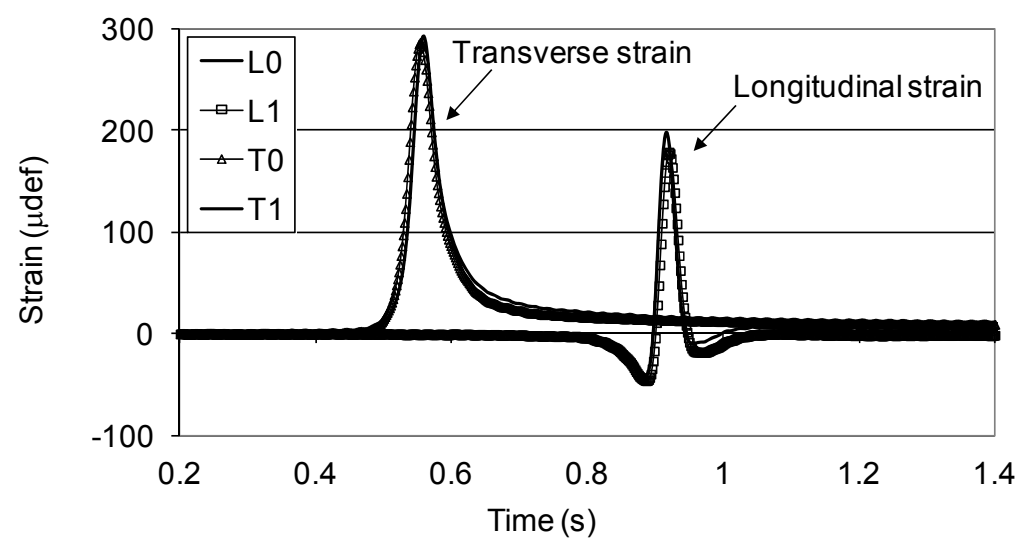

Figure 13. Signals of longitudinal and transverse strain gages under the centre of one wheel, at $21^{\circ} \mathrm{C}, 53000$ loads, $V=43 \mathrm{~km} / \mathrm{h}$

\subsubsection{Maximums of longitudinal and transverse strains}

There is a lateral wandering of the two arms of the APT : $+/-52.5 \mathrm{~cm}$. Maximums of longitudinal and transverse strains are measured for each position of the wheels.

For longitudinal gages :

- when $\mathrm{y}=0 \mathrm{~m}$, sensors are under the center of the dual wheel half axle

- when $y=-0.21 \mathrm{~m}$ or $0.21 \mathrm{~m}$, sensors are under the center of one wheel

For transverse gages :

- when $\mathrm{y}=0.105 \mathrm{~m}$, sensors are under the center of the dual wheel half-axle

- when $\mathrm{y}=-0.105 \mathrm{~m}$ or $0.315 \mathrm{~m}$, sensors are under the center of one wheel

Figure 14 presents maximums of longitudinal strains for each position of the wheels (lateral wandering), for the two strain gages glued on the grid and for a classical pavement strain gage, placed in the bituminous layer, at the same level. The shape of the curves is the same for the gages glued on the grid and the gage placed in the bituminous layer. There is only extension. The maximum strain is measured when the sensors are under the center of one wheel. The two types of gages give similar longitudinal strain levels (the strains are even slightly higher with the gages attached to the grid). So the grid does not seem to reduce the level of strain, compared with the response of the unreinforced pavement. 


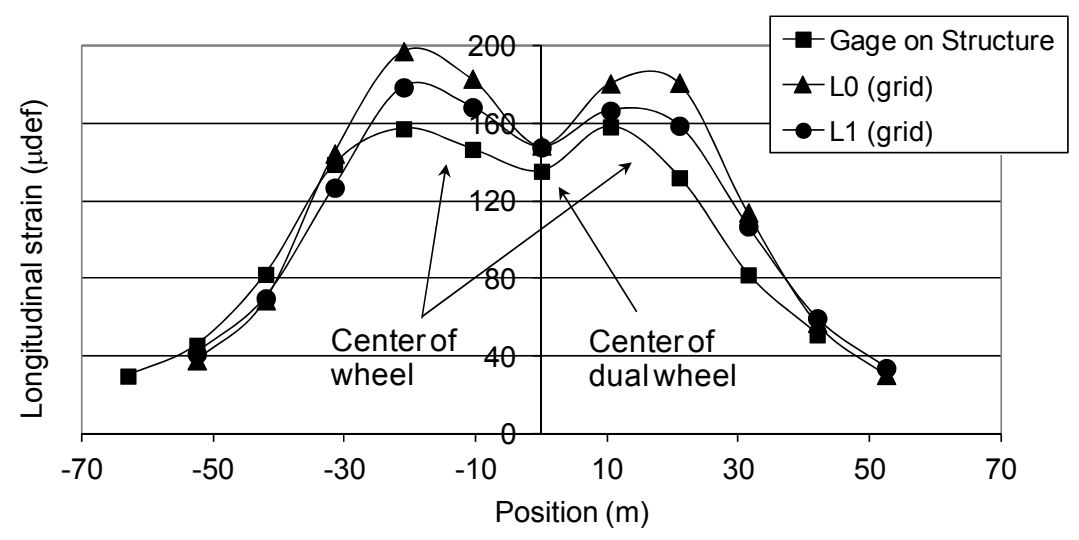

Figure 14. Maximum longitudinal strains in the structure and on the grid, for each position of the wheels, at $21^{\circ} \mathrm{C}, 53000$ loads, $V=43 \mathrm{~km} / \mathrm{h}$.

Figure 15 presents maximums of transverse strains for each lateral position of the wheels, for the two strain gages glued on the grid. The strains are in contraction far from the wheels, and under the centre of the dual wheel axle. They are in extension under the centre of each wheel. Results of transverse strains cannot be compared with those obtained with a classical gage, placed in the unreinforced structure, because the tansversal strain gage was broken during construction.

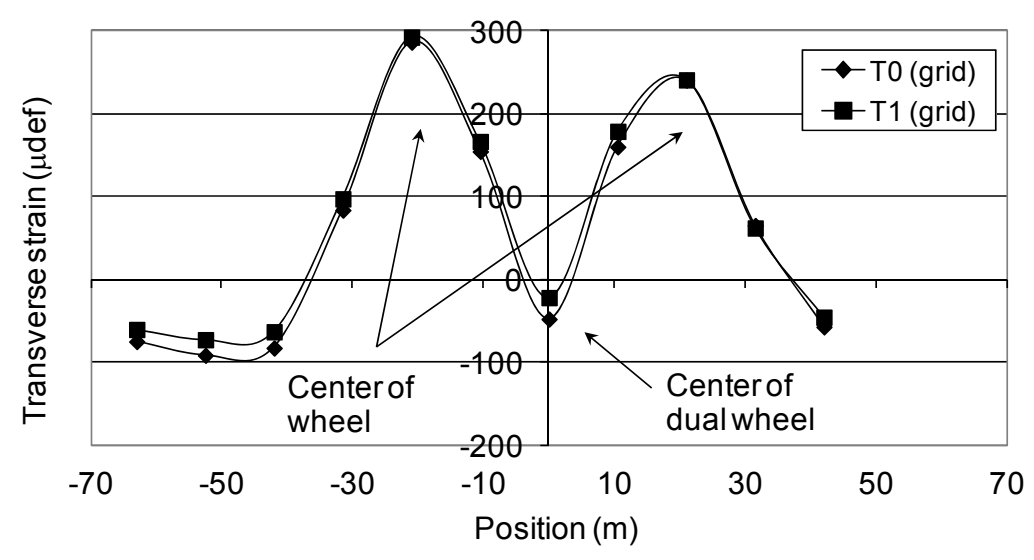

Figure 15. Maximum transverse strains on the grid, for each position of the wheels, at $21^{\circ} \mathrm{C}, 53000$ loads, $V=43 \mathrm{~km} / \mathrm{h}$. 
In conclusion, these first measurements demonstrate the possibility to measure the strains of the fiberglass grid, and indicate no significant strain reduction, due to the grid reinforcement, in a new pavement. The full scale test will be continued, in order to measure the evolution of the response of the grid, under traffic loading, and when the pavement starts to deteriorate. In a future research, it is also considered to place strains gages on the layer immediately below the grid in order to measure the effect of strain re-distribution induced by the reinforcement when the pavement deteriorates.

\section{Conclusion}

As presented in the literature review, glass fiber grid based reinforcement systems have been used for about 30 years, and have been the subject of many studies. Concerning laboratory behaviour, two main grid properties have to be evaluated: the adhesion of the grid to the asphalt material, and the resistance to cracking of the grid reinforced asphalt layer. Two main tests, which are relatively easy to perform, are largely used to evaluate these properties: the Leutner shear test to characterize adhesion and the four point bending test to characterize resistance to cracking. Another important property of glass fiber grids is their resistance to damage during construction, and a laboratory test simulating construction damage is also in development.

Laboratory tests on glass fiber grid reinforcement systems have shown mixed results, and it was shown that poor performance is mainly due to problems of bonding between the grid and the asphalt material. Various solutions have been proposed to improve the bonding, including association of the grid with a non woven geotextile and tack coat, or with a special adhesive film. The size of the grid mesh is also important: a too small size, in comparison with the maximum aggregate size, prevents the interlock of the aggregates from the two asphalt layers, and can lead to debonding.

In situ, glass fiber grids can be used for local repairs or for full width pavement reinforcement. Many results of field experiments have been reported, and have shown, in general, the efficiency of glass fiber grids for improving the resistance to cracking. Cases where poor performance was observed are mainly due to problems of bonding between the grid and the asphalt layers. Therefore, proper installation is essential to ensure an effective reinforcement.

If the efficiency of properly selected and installed glass fiber grids has been proven, the mechanisms of action of these reinforcements are still not fully understood, and the design of reinforced pavements remains mainly empirical. No practical, widely accepted, method for design of pavement overlays reinforced by glass-fiber grids is available, and this remains an important subject for research. 
Full scale tests on grid reinforced pavements carried out on the IFSTTAR Accelerated pavement testing facility have improved the knowledge of the behavior of these systems, and confirmed some of the conclusions of the literature review.

The test with new low traffic pavement structures has confirmed that a glass fiber grid, placed near the bottom of the asphalt layer, significantly improves the fatigue life, provided that there is good bonding with the asphalt layer. The results of this experiment also indicated no significant effect of the grid on pavement deflection, and resistance to rutting. To confirm the lack of influence on rutting, further tests could be performed at higher temperatures, and with the grid placed in the upper part of the asphalt layer

The test of maintenance techniques, performed in the FORMAT project, proved the efficiency of grid reinforcement, to improve the performance of thin asphalt overlays (only $2.5 \mathrm{~cm}$ thick).

Finally, the last part of the paper presented a solution of instrumentation of glass fiber grids by strain gages, to monitor their performance. First tests performed in a new pavement, have shown the possibility to measure the strains of the glass grid under traffic loading. First measurements indicated that in the new pavement, levels of strain in the grid and in the unreinforced asphalt layer are very similar. The experiment will be continued, to follow the behaviour of the grid during the whole life of the pavement.

\section{References}

Aldea C. M. and Darling J. R., Effect of Coating on FiberGlass Geogrid Performance $\square$ Proceedings of the $5^{\text {th }}$ International RILEM Conference, Limoges, 2004.

Al-Qadi I.L., Morian D.A., Stoffels S.M., Elseifi M., Chehab G. and Stark T., Synthesis on Use of Geosynthetics in Pavements and Development of a Roadmap to GeosyntheticallyModified Pavements $\square$, Federal Highway Administration (FHWA) report, 2008.

Arsenie I.M., Chazallon C., Themeli A., Duchez J.L. and Doligez D., Measurement and prediction model of the fatigue behavior of fiber glass reinforced bituminous mixture Proceedings of the $7^{\text {th }}$ International RILEM Conference on Cracking in Pavements, Delft, 2012.

Artières O., Bacchi M., Bianchini P., Hornych P. and Dortland G., Strain measurement in pavements with a fibre optics sensor enabled geotextile $\square$, Proceedings of the $7^{\text {th }}$ International RILEM Conference on Cracking in Pavements, Delft, 2012.

Autret P., de Boissoudy A.B., Gramsammer J.C., The circular test track of the Laboratoire Central des Ponts et Chaussées $\square$ First Results $\square$, Proceeding of the $6^{\text {th }}$ International Conference on Structural Design of Asphalt Pavements, Vol. 1, Ann Arbor, 1997, p. 550 561 .

Autret P and Gramsammer J.C., Le manège de fatigue du LCPC et linnovation $\square$, Revue Générale des Routes, No 680, 1990, p. 13-18. 
Baek J., Ozer H., Wang H., and Al-Qadi I.L., Effects of Interface Conditions on Reflective Cracking Development in Hot-Mix Asphalt Overlays $\square$, Road Materials and Pavement Design, Vol. 11, Iss. 2, 2010, p. 307-334.

Balay J.M., Kerzrého J.P. and Michaut J.P. Programme européen FORMAT, comparaison des tecniques dentretient. $2^{\text {ème }}$ partie $\square$, Revue Générale des Routes et aérodromes, No. 830, July-August, 2004, p. 77『82,

Bodin D., Modèle dendommagement cyclique: Application à la fatigue des enrobés bitumineux $\square \mathrm{PhD}$ thesis, Ecole Centrale Paris, 2002.

Brown S.F., Thom N.H., Sanders P.J., $\square$ A study of grid reinforced asphalt to combat reflective cracking $\square$ Journal of the Association of Asphalt Paving Technologies, Vol.70, 2001, p.543-571.

Buonsanti M., Leonardi G., Scopelliti F., Theoretical and computational analysis of airport flexible pavements reinforced with geogrids $\square$, Proceeding of the $7^{\text {th }}$ International RILEM Conference on Cracking in Pavements, Delft, 2012.

Bush A.J. and Brooks E.W., Geosynthetic Materials in Reflective Crack Prevention $\square$ Report No. OR-RD-08-01, ODOT, Salem, OR, 2007.

Button J.W. and Lytton R.L., Evaluation of Fabrics, Fibers and Grids in Overlays $\square$, 6th International Conference on the Structural Design of Asphalt Pavements, Ann Arbor, Michigan, 1987.

Button J.W. and Lytton R.L., Guidelines for Using Geosynthetics with Hot Mix Asphalt Overlays to Reduce Reflective Cracking $\square$ Journal of the Transportation Research Board, 2007, p. 111-119.

COST Action 348, Reinforcement of Pavements with Steel Meshes and Geosynthetics (REIPAS) $\square$, Final report, 2006.

Darling J.R. and Woolstencroft J.H., Fiberglass Geogrid Performance Evaluation for Retarding Reflective Cracking $\square$ Proceedings of the $4^{\text {th }}$ International RILEM Conference, Ottawa, Ontario, 2000.

Darling J.R. and Woolstencroft J.H., $\square$ A study of fiber glass pavement reinforcement used in different climatic zones and their effectiveness in retarding reflective cracking in asphalt overlays $\square$, Proceedings of the $5^{\text {th }}$ International RILEM Conference on Cracking in Pavements, Limoges, 2004.

de Bondt A.H., $\square$ Anti-Reflective cracking design of reinforced asphaltic overlays $\square, \mathrm{PhD}$ thesis, Delft University of Technology, 1999a.

de Bondt A.H., Required properties of reinforcing products $\square$, Oom Avenhorn Holding bv. Research \& Development - Background Information, 1999b.

de Bondt A.H., Innovative airfield pavement design $\square, 2^{\text {rd }}$ International Symposium on $3 D$ Finite Elements for Pavement Analysis, Design \& Research, Charleston, 2000.

de Bondt A.H., 20 years of research on asphalt reinforcement $\square$ Achivements and future needs $\square$, Proceeding of the $7^{\text {th }}$ International RILEM Conference on Cracking in Pavements, Delft. 2012. 
Doligez D., $\square$ An economical maintenance technic to preserve the road heritage at long terme $\square$, Technical seminar on Geosynthetics, Hammamet, 2009.

Elseifi M. and Bandaru R., Cost Effective Prevention of Reflective Cracking of Composite Pavement $\square$, FHWA Report LA.11/478, 2011.

Gramsammer J.C., Kerzrého J.P., Odéon H., The LCPC $\lessdot$ S A.P.T. Facility: Evaluation of fifteen years of experimentation $\square$, International Conference of Accelerated Pavement Testing, Reno, Nevada, October 1999.

Hakimzadeh S., Kebede N.A., Buttlar W.G., Ahmed S., Exline M., Development of fractureenergy based interface bond test for asphalt concrete $\square$, Road Materials and Pavement Design, Vol. 13, Iss. sup1, 2012, p. $76 \square 87$.

Hornych P., Kerzrého J.P., Chabot A., Bodin D., Balay J.M., Deloffre L., The LCPC $\varangle$ ALT facility contribution to pavement cracking knowledge $\square$, Proceding of the $6^{\text {th }}$ International RILEM Conference, Chicago, 2008.

Hornych P., Kerzrého J.P., Sohm J., Chabot A., Trichet S., Joutang J.L., Bastard N., Full scale tests on grid reinforced flexible pavements on the french fatigue carrousel $\square$, Proceeding of the $7^{\text {th }}$ International RILEM Conference on Cracking in Pavements, Delft. 2012.

$\mathrm{Hu}$ X. and Walubita L.F., $\square$ Modelling Tensile Strain Response in Asphalt Pavements $\square$, Road Materials and Pavement Design, Vol. 10, Iss. 1, 2009, p. 125-154.

Hufenus R., Rüegger R., Flum D. and Sterba I.J., Strength reduction factors due to installation damage of reinforcing geosynthetics $\square$ Journal of Geotextiles and Geomembranes 23, 2005, p. 401匹424.

Jaecklin F.P. and Scherer J., $₫$ Asphalt reinforcing using glass fibre grid, Glasphalt $\square$ Proceedings of the $3^{\text {rd }}$ International RILEM Conference on Reflective Cracking in Pavements : Design and Performance of Overlay Systems, Maastricht, 1996.

Kerzrého J.P., Michaut J.P. and Hornych P., Enrobé armé de grille en fibre de verre $\square$ Test sur le manège de fatigue de 1IFSTTAR $\square$ Revue Générale des Routes et aérodromes, N890, December $2010 \square$ January 2011, p. 48-51.

Kerzrého J.P., Hornych P. and Sohm J., $\square$ Accelerated loading test on structures reinforced by geogrids with the FABAC machines $\square$ Technical report, IFSTTAR, 2011.

Khay M. and Giraud H., $\square$ Voies de circulation et fondations: Derniers développements $\square$ 5th Rencontres Géosynthétiques Francophones, 2003/2004.

Lee S.J., $\square$ Mechanical performance and crack retardation study of a fiber glass grid reinforced asphalt concrete system $\square$ Canadian Journal of Civil Engineering, Vol. 35, 2008, p. 10421049.

Leutner R., Untersuchung des Schichtenverbundes beim bituminösen Oberbau $\square$, Bitumen 41-3, 1979, p. 84-91.

Lytton R.L., Reinforcing fiberglass grids for asphalt overlays $\square$, Texas Transportation Institute Report for Bay Mills Limited, Texas A\&M University, College Station, Texas, 1988. 
Lytton R.L., Use of geotextiles for reinforcement and strain relief in asphalt concrete Journal of Geotextiles and Geomembranes, Vol. 8, 1989, p. 217-237.

Marks V.J., Glasgrid Fabric to Control Reflective Cracking $\square$ Iowa Department of Transportation, Experimental Project IA 86-10, Ames, Iowa, 1990.

Michaut J.P., Balay J.M., Kerzrého J.P., Programme européen FORMAT, comparaison des tecniques dentretient. $1^{\text {ère }}$ partie $\square$, Revue Générale des Routes et aérodromes, No. 827, April 2004, p. $58 \square 63$

NF EN 15381, Geotextiles and geotextile-related products $\square$ Characteristics required for use in pavements and asphalt overlays $\square$, European standard $\square$ French standard, 2008.

Nguyen M.L., Balay J.M., Kerzreho J.P., $\square$ Projet ANR Recyroute $\square$ Expérience sur le manège de fatigue dIFSTTAR $\square$, Final report, 2012.

Penman J. and Hook K.D., The use of geogrids to retard reflective cracking on airport runways, taxiways and aprons $\square$ Proceedings of the $6^{\text {th }}$ International RILEM Conference on Cracking in Pavements, Chicago, 2008.

Piber H., Canestrari F., Ferrotti G., Lu X., Millien A., Partl M.N., Petit C., Phelipot-Mardelé A., Raab C., RILEM interlaboratory test on interlayer bonding of asphalt pavements Advanced Testing and Characterization of Bituminous Materials - Loizos, Partl, Scarpas and Al-Qadi (eds), Taylor \& Francis Group, London, 2009, p. 1181-1189.

Plug C.P. and de Bondt A.H., $\square$ Adhesion of reinforcement grids in asphalt overlays $\square 5^{\text {th }}$ World congress on emulsion, Lyon, 2010.

Powell R.B., Installation and performance of a fiberglass geogrid interlayer on the NCAT Pavement Test Track $\square$ Proceedings of the $6^{\text {th }}$ International RILEM Conference on Cracking in Pavements, Chicago. 2008.

prEN ISO 10722-1, Geotextiles and geotextile-related products $\square$ procedure for simulating damage during installation $\square$ Part 1: installation in granular materials $\square$, CEN, European Committee for Standardization, 2004.

Raab C., Partl M.N. and Abd El Halim A. O., Evaluation of Interlayer Shear Bond Devices for Asphalt Pavements $\square$, Baltic Journal of Road and Bridge Engineering. 4(4), 2009, p. 176-195.

Rathmayer H.G., Reinforcement of Pavements with Steel Meshes and Geosynthetics $\square$ Proceeding of Design and Construction of Pavements and Rail Tracks - Geotechnical Aspects and Processed Materials, Taylor \& Francis, 2007.

Scullion T. and Von-Holdt C., Performance report on jointed concrete pavement repair strategies in Texas $\square$, FHWA/TX report : 05/0-4517-1, Texas, 2004.

South Africa, $\square$ Technical Guideline: Asphalt Reinforcement for Road Construction $\square$, Asphalt Academy, 2008.

Steinberg M.L., Geogrid as a Rehabilitation Remedy for Asphaltic Concrete Pavements $\square$ Transportation Research Record: Journal of the Transportation Research Board, No. 1369, Transportation Research Board, Washington, D. C., 1992, p. $54 \square 62$. 
30 Road Materials and Pavements Design. Volume X $\square$ No X/2013

Vanelstraete A. and Franken L., Prevention-of-Reflective-Cracking-in-Pavements $\square$, RILEM TC 157 PRC report, 1997.

Virgili A., Canestrari F., Grilli A., Santagata F.A., Repeated load test on bituminous systems reinforced by geosynthetics $\square$, Geotextiles and Geomembranes, 27, 2009, p. 187-195. 